\title{
Somatically heritable switches in the DNA modification of $M u$ transposable elements monitored with a suppressible mutant in maize
}

\author{
Robert Martienssen, ${ }^{1}$ Alice Barkan, ${ }^{2}$ William C. Taylor, ${ }^{3}$ and Michael Freeling \\ Department of Genetics, University of California, Berkeley, California 94520 USA
}

\begin{abstract}
Many transposable elements in maize alternate between active and inactive phases associated with the modification of their DNA. Elements in an inactive phase lose their ability to transpose, their ability to excise from reporter alleles and, in some cases, their ability to enhance or suppress mutant phenotypes caused by their insertion. The maize mutant hcf106 is a recessive pale green seedling lethal caused by the insertion of the transposable element Mu1. We show that the hcf106 mutant phenotype is suppressed in lines that have lost $\mathrm{Mu}$ activity. That is, homozygous hcf106 seedlings are dark green and viable when transposable elements belonging to the Robertson's Mutator family are modified in their terminal inverted repeats, a diagnostic feature of inactive lines. This property of the mutant phenotype has been used to follow clonal leaf sectors containing modified $\mathrm{Mu}$ elements that arise from single somatic cells during plant development. The distribution of these sectors indicates that epigenetic switches involving $M u$ DNA modification occur progressively as the meristem ages.
\end{abstract}

[Key Words: Transposable elements; maize; $h c f 106 ; M u$ elements]

Received April 7, 1989; revised version accepted January 9, 1990.

DNA modification has been implicated in a variety of phenomena involving heritable changes in the control of gene expression (Holliday 1987; Cedar 1988). Examples include the somatic inactivation of $\mathrm{X}$ chromosomes in mammals (Yen et al. 1984; Lock et al. 1987), and changes in the pattern of DNA methylation in germ line cells associated with parental genome imprinting (Swain et al. 1987; Surani et al. 1988). In plants, DNA modification is associated with the loss of genetic activity of the maize transposable elements Ac (Activator), Spm (Suppressor-mutator), and $M u$ (Robertson's Mutator) (Chandler and Walbot 1986; Chomet et al. 1987; Banks and Fedoroff 1988). In both plants and animals, these phenomena are thought to reflect epigenetic mechanisms involved in normal development (Holliday 1987; Fenormal development (Holliday 1987; Fedoroff 1989).

We have examined the developmental pattern of $\mathrm{Mu}$ DNA modification in maize leaves using a suppressible mutation. Suppressible mutations caused by transposable elements have been described at the molecular level in yeast (Winston et al. 1984) and Drosophila (Kubli 1986), as well as in maize (Masson et al. 1987; SchwarzSommer et al. 1987). Suppressible phenotypes in maize

Present addresses: ${ }^{1}$ Cold Spring Harbor Laboratory, Cold Spring Harbor New York 11724 USA; ${ }^{2}$ Department of Plant Biology, University of California, Berkeley, California 94520 USA; ${ }^{3}$ CSIRO Division of Plant Industry, Canberra ACT, Australia. that are induced by McClintock's Spm element are influenced both by the presence of an autonomous element and by its phase of activity (McClintock 1958, 1965). In this paper we describe the first suppressible mutation in maize controlled by $M u$ elements and show that it responds to changes in transposon activity associated with DNA modification.

$M u$ transposable elements are largely responsible for the high frequency of unstable mutations recovered from Robertson's Mutator lines (Robertson 1978; Bennetzen 1984; Alleman and Freeling 1986). Mu elements comprise a large family of transposable DNA sequences related by their terminal inverted repeats (for review, see Freeling 1988). The most common $M u$ elements are the 1.4-kb Mu1 element and the related element Mu1.7 (Bennetzen et al. 1984; Taylor and Walbot 1987), but no autonomous element similar to $A c$ or Spm has been unequivocally identified for $\mathrm{Mu}$. Robertson's Mutator lines can lose activity in a non-Mendelian "change of phase," defined by the loss of $M u$ transposition (Robertson 1983; Bennetzen 1987), the loss of excision from reporter alleles (Walbot 1986), and the loss of extrachromosomal $\mathrm{Mu}$ circles (Sundaresan and Freeling 1986). Inactive $\mathrm{Mu}$ tator lines derived in this way contain a high proportion of $M u 1$ elements whose terminal inverted repeats are insensitive to digestion with the restriction enzyme Hinfl (Chandler and Walbot 1986). Active lines contain only unmodified Mu1 elements, which are sensitive to HinfI 
digestion. A number of other restriction enzymes sensitive to cytosine methylation also fail to digest Mu1 sequences in inactive lines (Bennetzen 1987).

The photosynthetic mutant hcf106 contains a single recessive nuclear mutation that prevents the normal assembly of photosynthetic electron transport complexes and causes aberrant thylakoid membrane organization (Barkan et al. 1986; Martienssen et al. 1987). Consequent reductions in chloroplast pigment levels result in pale green mutant seedlings. These emit an increased fluorescence when illuminated with ultraviolet light (thus, the designation hcf for high chlorophyll fluorescence), as they are unable to channel harvested light energy into photosynthetic electron transport (Miles 1982). Homozygous mutant seedlings die $\sim 3$ weeks after germination when seed reserves are exhausted. Heterozygous plants survive to maturity, enabling propagation of the mutation.

hcf106 arose in a Robertson's Mutator line and showed signs of somatic instability (namely, dark green sectors), suggesting that it was caused by the insertion of a $M u$ transposable element. Heterozygous plants were outcrossed in successive generations to the inbred line $\mathrm{B} 73$, resulting in segregation of the 20-40 Mu1 elements found in these lines (Martienssen et al. 1987; for an example, see Fig. lb). A 3.7-kb SstI fragment containing sequences homologous to the transposable element $M u 1$ was found by Southern analysis in every mutant seedling derived from these outcrosses (Martienssen et al. 1989|. The 3.7-kb fragment was cloned into a phage vector and was subsequently identified by other criteria as part of the hcf106 gene (Martienssen et al. 1989).

We show that in plants homozygous for hcf106, DNA modification of Mu1 elements is correlated with suppression of the mutant phenotype. That is, homozygous plants adopt a wild-type phenotype when their Mu1 elements are inactive and modified, but a mutant phenotype when they are active and unmodified. Thus, $M u$, like other transposons, can subvert gene regulation in a reversible fashion. We have used this phenotype to show that changes from active to inactive phase can occur in somatic cells leading to clonal sectors of wild-type tissue that contain modified Mu1 elements. The distribution of these sectors suggests that phase changes occur progressively in meristematic cells, but can be reversed zygotically in crosses to active plants. This pattern of inheritance may explain the greater efficiency with which $M u$-active plants can reactivate $M u$-inactive lines when they are used as the female, rather than the male, parent (Walbot 1986; Bennetzen 1987). It may also reflect the different strategies of plants and animals in correcting epigenetic defects that arise during development.

\section{Results}

hcf 106 is suppressed in plants containing modified Mul elements

A portion of the pedigree resulting from the self-pollinating and outcrossing of plants heterozygous for $h c f 106$ is shown in Figure 1a. Two-thirds of the mature plants derived by self-pollinating heterozygotes /self families in Fig. 1a) were expected to carry the mutant allele. However, in some families, only a small number of plants (if any) produced mutant progeny after self-pollination (Fig. 1a). Even so, the mutant allele, which was marked by a 3.7-kb Sst fragment (discussed previously), segregated at the expected Mendelian ratio (Fig. 1a; data not shown). Consequently, a number of "wild-type" plants were identified that failed to segregate any mutant seedlings on self-pollination but still carried the mutant allele (solid circles in Fig. 1a).

There were two alternative explanations. First, these wild-type plants may have been revertants, or other derivatives, of the hcf106 mutation. This seemed unlikely because these plants (solid circles in Fig. 1b) did not carry a detectable rearrangement at the hcf106 locus (i.e., they had the $3.7-\mathrm{kb}$ fragment). Alternatively, the mutant allele may have been suppressed in wild-type plants so that their progeny were unable to express the mutant phenotype. By analogy with McClintock's Suppressor-mutator system, suppression may have been mediated by a change of phase from active to inactive $M u$.

The activity of $M u$ elements within a plant can be determined by examining the modification of the HinfI restriction sites in the terminal inverted repeats of each Mu1 element (Chandler and Walbot 1986; Walbot 1986). $\mathrm{Mu} 1$ elements from $\mathrm{Mu}$-active plants contain only unmodified Hinfl sites, whereas a high proportion of those from $\mathrm{Mu}$-inactive plants have modified sites. Unmodified $M u 1$ homologous elements fall into two size classes, Mu1 and Mu1.7, which yield fragments of 1.3 and $1.7 \mathrm{~kb}$, respectively, when digested with HinfI and hybridized with internal probes from $M u 1$ (Barker et al. 1984; Bennetzen et al. 1984). In contrast, modified elements are present on larger HinfI fragments, as the HinfI sites in the inverted repeats are not sensitive to digestion.

The suppression model predicts that among those plants carrying the mutant allele, "wild-type" plants (i.e., those that give rise to no mutant progeny on selfpollination) should contain modified elements, whereas mutant seedlings should not (Fig. 1). Figure 1c shows that Mu1 elements in each of the suppressed families shown (solid circles) were modified as predicted. The only family that did not contain modified elements was derived from a wild-type plant that did not carry the mutant allele (open circle). Analysis of 71 mutant and 22 suppressed plants gave results consistent with the suppression model: Mutants had only unmodified elements, whereas 21 of 22 suppressed plants had modified elements (Table 1). The exceptional suppressed plant with unmodified elements was heterozygous but gave no mutant progeny on selfing (0 of 219). About half of its progeny also had unmodified elements [shown in Fig. 2, lanes $d$ (modified) and e (unmodified)]. However, these plants appeared to be $\mathrm{Mu}$-inactive, as no new fragments hybridizing to $\mathrm{Mu} 1$ were detected that were not already present in the heterozygous parent (lanes $\mathrm{a}, \mathrm{b}$, and $\mathrm{c}$ in 
a
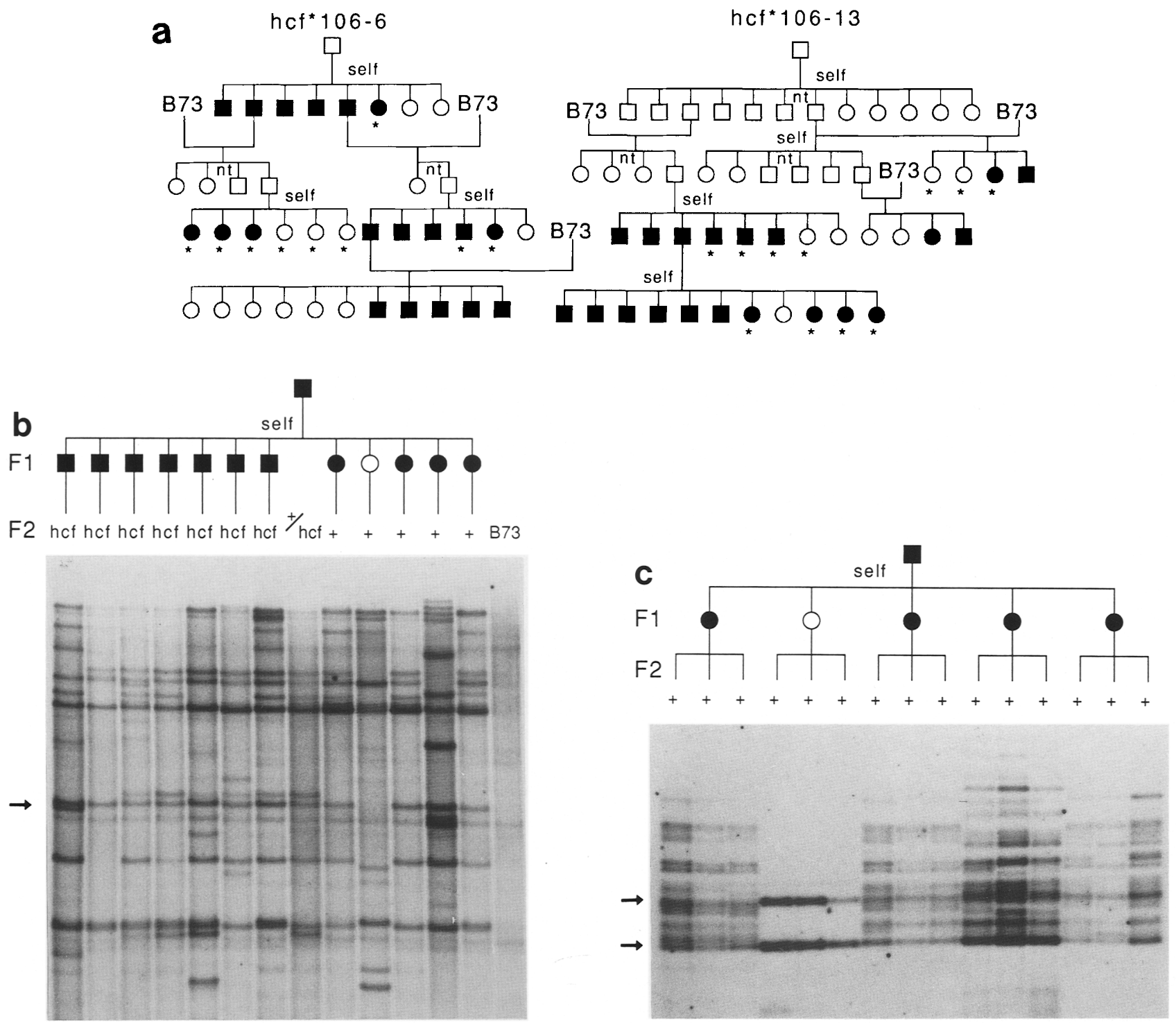

Figure 1. Pedigree analysis of hcf106. $\{a\}$ A portion of the pedigree obtained by self-pollinating and outcrossing the original hcf106 mutation is shown (see Methods). Each symbol represents a mature plant: Mutant seedlings died 3 weeks after germination and are not shown. Squares represent plants that segregated mutant seedlings upon self-fertilization; circles represent plants that gave no mutant progeny in the $\mathrm{F}_{1}$. Plants that were predicted to carry the mutant allele by Southern analysis are shown as solid symbols (whether heterozygous or homozygous). Plants carrying modified Mu1 elements are designated with an asterisk (*). Families labeled nt were tested for neither character. Thus, suppressed plants that carried the mutant allele but did not segregate mutants on self-pollination are represented by solid circles. All but one of these had modified elements (Table 1). (b) An autoradiograph of a Southern blot showing segregation of the mutant allele in a family from $a$. DNA from the heterozygous parent $(+/$ hcf) and from mutant (hcf) and normal $(+) F_{2}$ seedlings derived by self-pollinating each member of the family was digested with SstI and subjected to Southern analysis using an internal Mu1 fragment as a probe. The arrow indicates the 3.7-kb fragment that marks the mutant allele. All of the heterozygotes (squares), and four of the five wild-type plants that gave no mutant progeny in the $\mathrm{F}_{2}$ (circles) carried this fragment (solid symbol). (c) An autoradiograph of a Southern blot showing the presence of modified elements in suppressed plants. DNA was extracted from three $\mathrm{F}_{2}$ seedlings derived by self-pollinating each of the five wild-types in the family shown in $b$. These 15 DNA samples were digested with HinfI and subjected to Southern analysis, as in $b$. Fragments derived from unmodified Mu1 and Mu1.7 elements migrate at 1.3 and $1.7 \mathrm{~kb}$, respectively (arrows). Modified Mu1 elements are found on larger fragments.

Fig. 2). The presence of new fragments (i.e., transposed Mu1 elements) and the consequent increase in element copy number are thought to be diagnostic of $\mathrm{Mu}$ activity (Alleman and Freeling 1986; Bennetzen 1987). Thus, the exceptional heterozygote appeared to have lost $M u$ ac- tivity by a process that does not involve Hinfl modification (Bennetzen et al. 1988).

To establish whether the Mu1 element at the hcf106 locus was modified in suppressed plants, probes from the locus were used in Southern hybridizations. A re- 
Table 1. DNA modification of Mul elements from mutant and suppressed plants

\begin{tabular}{lcc}
\hline & $\begin{array}{l}\text { HinfI } \\
\text { modified }\end{array}$ & $\begin{array}{l}\text { HinfI } \\
\text { unmodified }\end{array}$ \\
\hline Mutant seedlings & 0 & 71 \\
Nonmutant sibs & 30 & 40 \\
Suppressed plants & 21 & 1 \\
\hline
\end{tabular}

DNA was prepared from individual mutant seedlings and suppressed plants and analyzed for Mu1 modification at the HinfI sites in the terminal inverted repeats, as described in Fig. 1. Suppressed plants carried the mutant $h c f 106$ allele (as judged by Southern blotting using SstI) but failed to produce mutant progeny on selfing (see Fig. 1). DNA was also prepared from heterozygous and wild-type plants from segregating families (nonmutant sibs). Some heterozygotes with modified elements gave rise to a reduced number of mutant seedlings on self-pollination, but these mutants had only unmodified elements (see text).

striction map of the DNA surrounding the Mu1 element at the hcf106 locus (Martienssen et al. 1989) is shown in Figure 3 . The transcribed region (identified by Northern analysis with single-stranded probes) is shown as a wavy line. Only the first $400 \mathrm{bp}$ of the $1.2-\mathrm{kb}$ transcription unit is represented on the cloned genomic DNA fragment. The Mu1 element lies within the 5 '-untranslated region close to one of three mRNA initiation sites (A. Barkan and R. Martienssen, in prep.).

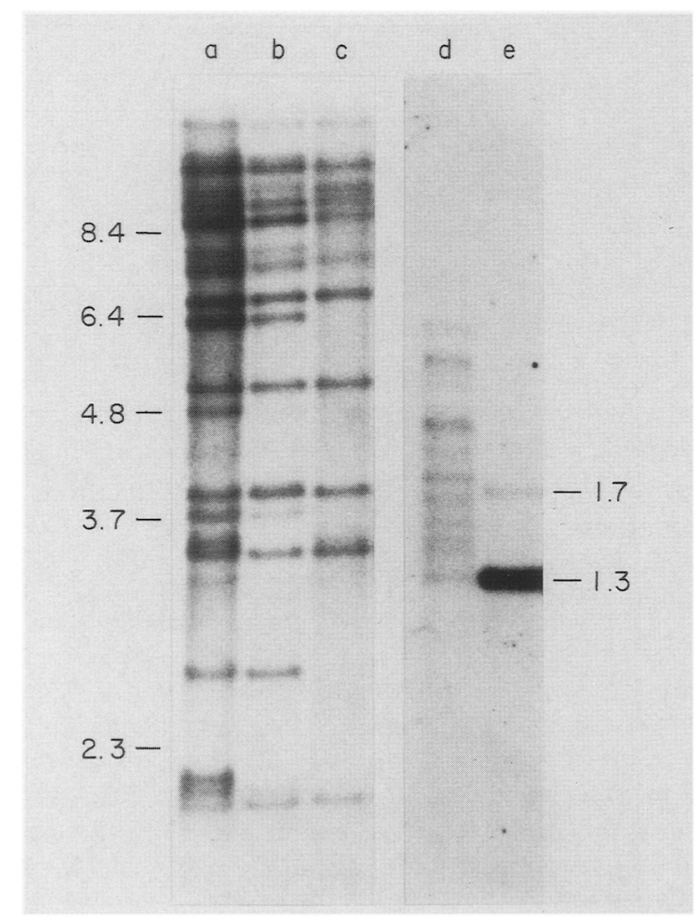

Figure 2. Absence of DNA modification and $M u$ transposition in exceptional suppressed plants. DNA from the exceptional suppressed heterozygote (lane a), and two randomly chosen progeny (lanes $b$ and $c$ ) digested with SstI and probed with $M u 1$. No new bands and no increase in copy number are observed in the progeny. Lanes $d$ (modified) and $e$ (unmodified) show the same samples as lanes $b$ and $c$, but digested with Hinfl.
A hybridization probe from the transcribed region was used to determine whether Hinfl sites in and around the Mu1 element at the hcf106 locus were methylated in suppressed plants. This probe hybridizes to five HinfI fragments in DNA from homozygous mutant plants (Fig. 3 , lanes $b-e)$. The smallest of these (a 300-bp fragment labeled hcf in Fig. 3) is bounded by HinfI sites from the gene and Mu1, as shown above the restriction map. The other four fragments are derived from the coding region of the gene and from a second hybridizing locus of unknown function. These fragments are also found in the inbred line B73 that does not have a Mu1 element at the locus (lane h). In contrast, the 300-bp Mu1:hcf106 fragment found in mutant seedlings is replaced by a 360-bp HinfI fragment in B73 (labeled + in Fig. 3, lane h). Apart from the Mu1 element, the restriction map of the wildtype allele from B73 is the same as that of the mutant allele around the insertion site (R. Martienssen, unpubl.).

In DNA from a homozygous suppressed plant (lane $\mathrm{f}$ ), the 300-bp hcf fragment is replaced by bands of 1.65 and $2.7 \mathrm{~kb}$ (hcf arrowheads). These represent fragments in which the HinfI sites within $M u 1$ and a flanking site 100 bp upstream are modified and resistant to digestion. DNA from a homozygous progeny seedling from the exceptional suppressed plant that had unmodified Mu1 elements was also analyzed for Hinfl modification at the locus (lane a). The pattern of HinfI fragments was indistinguishable from that of the mutant seedlings (lanes $\mathrm{b}-\mathrm{e}$ ), showing that the proximal HinfI site in Mu1 was unmodified in this plant.

Thus, homozygous suppressed plants that contain modified Mu1 elements ( $95 \%$ of those observed) also have a modified element at the hcf106 locus. However, this modification is not required for suppression in all cases, as suppressed progeny from an exceptional plant have unmodified HinfI sites, including the one at the locus.

\section{The mutant phenotype can be restored in crosses to Mu-active lines}

Inactive $M u 1$ elements can be reactivated by crossing to $\mathrm{Mu}$-active plants (Walbot 1986). Reactivation can be assayed by destabilization of mutable reporter alleles (Walbot 1986), transposition (Robertson 1978; Bennetzen et al. 1987), and demodification of Mu1 elements (Chandler and Walbot 1986; Bennetzen 1987). It was postulated that if the suppressed allele were controlled by the activity of Mu1 elements in the cell, then the mutant phenotype might be restored to the $\mathrm{Mu}$-active progeny of crosses between $\mathrm{Mu}$-active and suppressed plants.

Seventeen crosses between $M u$-active and suppressed plants were analyzed, nine of which gave rise to mutant progeny in the $F_{1}$ (see Methods). In contrast, none of the suppressed plants gave rise to mutant progeny when they were self-pollinated (Table 2). This experiment confirmed that the suppressed lines carried the mutant allele and not a revertant allele. Furthermore, it sug- 


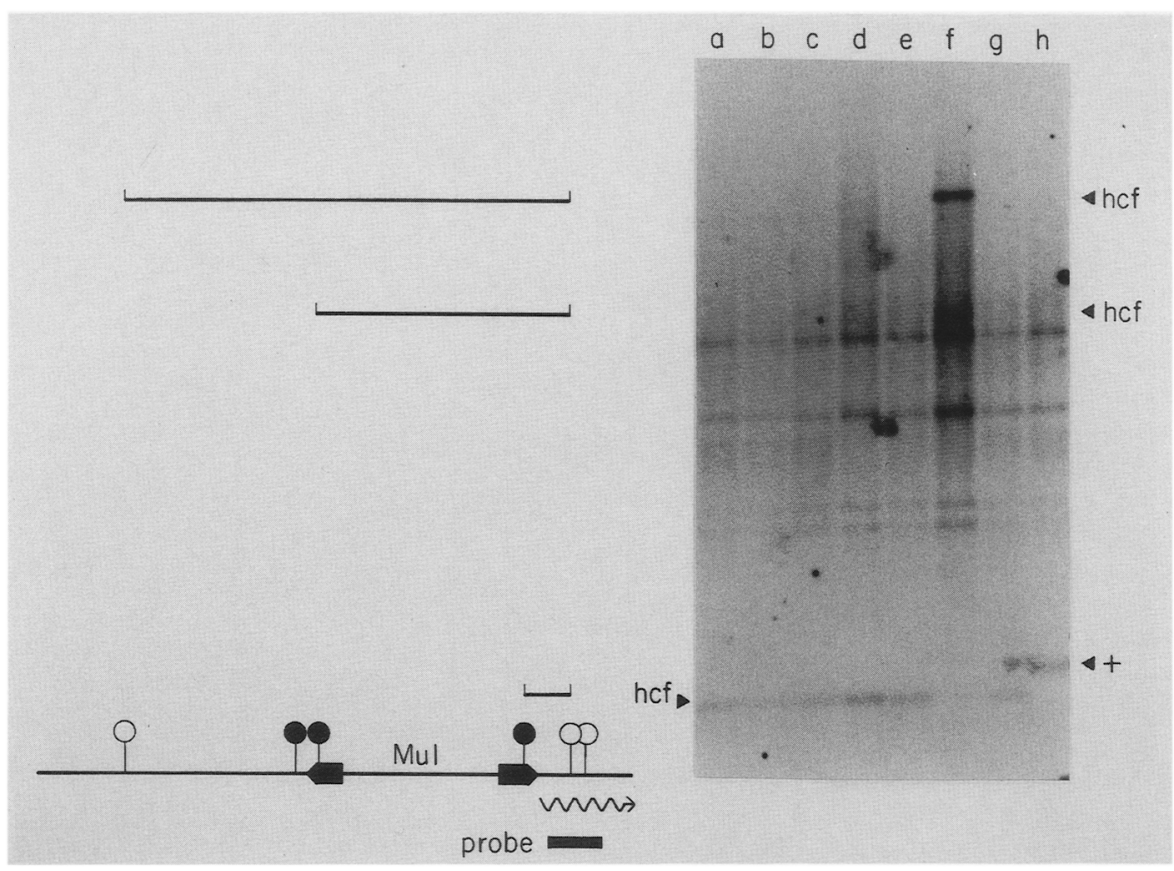

Figure 3. DNA modification at the $h c f 106$ locus. DNA from mutant (lanes $b$-e, and $g$ ), wild-type (lane $h$ ), homozygote suppressed (lane $f$ ), and exceptional homozygote-suppressed seedlings (lane $a$ ) digested with HinfI and probed with a flanking probe from the hcf106 locus. A restriction map of the locus shows the position of the probe relative to the transcript (wavy line) and the HinfI restriction sites in and around $\mathrm{Mu} 1$ (circles). Sites affected by modification in the suppressed allele are indicated by solid circles. Fragments of $2.7,1.65$, and $0.3 \mathrm{~kb}$, containing modified and unmodified sites are, labeled hcf and shown above the restriction map. The corresponding fragment from the inbred B73 is labeled +. Because of the close proximity of the two downstream HinfI sites (separated by only $50 \mathrm{bp}$ ), it is not known whether the proximal site is modified or not. Sizes were determined by comparison with $\lambda$ DNA digested with HindIII (not shown).

gested that recovery of the mutant phenotype was associated with the restoration of $M u$ activity. This was confirmed by analyzing DNA from individual seedlings for Mu1 element modification. Figure 4 shows that mutant (hcf) seedlings - whether they were derived by self-pollination of active parents or from the $F_{1}$ progeny of reactivation crosses-did not contain modified Mu1 elements. In contrast, wild-type $(+)$ seedlings derived by self-pollinating suppressed plants contained modified Mu1 elements.

Table 2. Reactivation crosses between Mu-active and suppressed plants

\begin{tabular}{lccc}
\hline & $\begin{array}{l}\text { Number } \\
\text { of crosses }\end{array}$ & $\begin{array}{l}\text { Total } \\
\text { progeny }\end{array}$ & $\begin{array}{l}\text { Number } \\
\text { of mutants }\end{array}$ \\
\hline Mu-active $\times$ suppressed F1 & 9 & 273 & 62 \\
Suppressed parent selfed & 9 & 293 & 0 \\
$M u$-active parent selfed & 4 & 36 & 8 \\
\hline
\end{tabular}

Of 17 crosses between $\mathrm{Mu}$-active and suppressed parents, 9 gave rise to mutant progeny $(\mathrm{Mu}$-active $\times$ suppressed $\mathrm{F} 1)$. In each case, the suppressed parent of the cross was also self-pollinated to ensure that no mutant progeny segregated on selfing (suppressed parent selfed). In four cases, the $\mathrm{Mu}$-active parent was also self-pollinated on a second ear to confirm that mutant progeny were recovered from each parent and segregated at the expected 3:1 ratio ( $\mathrm{Mu}$-active parent selfed). The results from each class of cross have been pooled and are tabulated here.
In each of the three representative crosses shown in Figure 4 , mutant seedlings were obtained in the $F_{1}$ generation when the active parent was used as a female. In cross 1 , mutant seedlings were also recovered when the active parent was used as a male. However, in cross 2 , no mutant seedlings were recovered when the active parent was used as a male. DNA isolated from randomly chosen wild-type progeny from this $F_{1}$ population contained modified Mu1 elements (e.g., cross 2, third lane), suggesting that reactivation had failed to occur in this reciprocal cross.

Progeny from the exceptional suppressed heterozygote with unmodified elements were also crossed to active lines segregating $h c f 106$ to reactivate $\mathrm{Mu}$. Of six such crosses, three yielded mutant progeny (total 27 of 100 screened). In contrast, none of the suppressed parents yielded mutants on selfing. This showed that the exceptional plants also carried the mutant allele, so that the mutant phenotype was, indeed, suppressed. The mechanism of suppression in this case did not correlate with Hinfl modification (see earlier).

These results show that reactivation of the Mu1 elements carried by suppressed plants resulted in the restoration of mutant phenotype. On the rare occasions that this reactivation failed to occur-such as in one of the reciprocal crosses in cross 2 - no mutant seedlings were observed. Most of the reactivation crosses gave rise to one-quarter mutant progeny in the $F_{1}$ generation, sug- 
Figure 4. Reactivation crosses between active and suppressed plants. Three crosses between active plants (squares) and suppressed plants (circles) are shown diagrammatically. The genotype of each parent, determined by both molecular and genetic criteria, is represented by either solid (homozygote) or hatched (heterozygote) symbols. Crosses 1 and 2 were performed reciprocally, pollen from each parent was used to fertilize one ear on the other parent and also to self-fertilize the second ear. The number of mutant progeny obtained in each separate $F_{1}$ is shown as a proportion of the total number of progeny (crosses 1 and 3 are pooled data from two similar crosses). DNA from several $F_{1}$ seedlings was analyzed for Hinfl modification, as described in Fig. 1c, and a representative mutant (hcf) or normal $(+)$ seedling is shown. Fragments derived from unmodified Mu1 elements migrate at 1.7 and 1.3 $\mathrm{kb}$ (arrows). Complete digestion was confirmed as in Fig. 1.

gesting that both parents were heterozygous. However, in at least two cases, a $1: 1$ ratio in the $F_{1}$ was observed (e.g., cross 3, Fig. 4). In these cases, it was concluded that the suppressed parent was homozygous for the hcf106 mutant allele, as subsequently confirmed by Southern analysis (Martienssen et al. 1989). Even so, these plants failed to express the mutant phenotype and lived to maturity. Thus, $h c f 106$ represents a $\mathrm{Mu}$-suppressible mutation. Plants homozygous for the mutant allele can only express the mutant phenotype when the Mu1 elements in the genome are unmodified and in an active phase.

DNA modification of Mul and suppression of the mutant phenotype are clonally inherited in mosaic plants

Occasionally, mutant seedlings were observed that had large sectors of wild-type leaf tissue, visible as dark green, low-fluorescent sectors on pale green, high-fluorescent mutant leaves. DNA was extracted from dark green sectors and adjacent pale green tissue from three independent mosaic plants. These sectors were much larger than those that typically result from $\mathrm{Mu}$-induced excision (Lillis and Freeling 1986; Martienssen et al. 1989|, and Southern analysis showed no sign of the revertant allele diagnostic of revertant sectors (data not shown). Each sample was then analyzed for Mu1 modification, and an example is shown in Figure 5 (left). Although the pale green mutant sector had only unmodified elements (lane b), the dark green sector had modified elements (lane a). This shows that individual cell lineages can lose $\mathrm{Mu}$ activity, whereas adjacent tissue retains active $M u$. Rehybridization of the same blot with chloroplast DNA sequences showed that these differences were not due to partial enzyme digestion (Fig. 5, right).

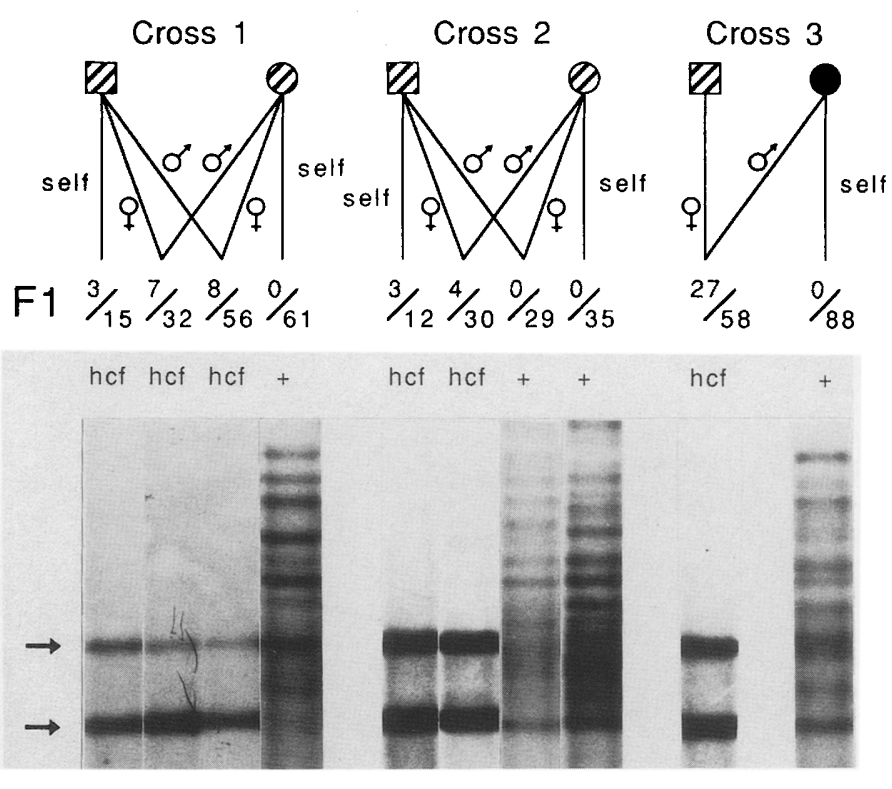

An example of a quarter-leaf sector is shown in Figure 6. This sector was observed in the second and successive leaves of a mutant seedling and passed from the middle of one leaf to the margin of the next, demonstrating that the sector was clonal and probably arose from a single meristematic cell (Coe and Neuffer 1978). In contrast, sectors thought to be associated with transposon excision comprised only a few cells and appeared as dark green flecks in mutant, pale green tissue (barely visible in Fig. 6a). DNA was prepared from the large dark green

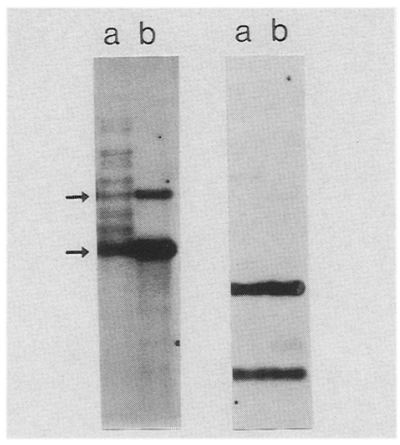

Figure 5. Somatically inherited modification of Mu1 elements. DNA was prepared from tissue derived from a dark green stripe (lane $a$ ) and adjacent pale green material (lane $b$ ) from a single leaf from a mosaic plant. Each sample was digested with HinfI and subjected to Southern analysis, as in Fig. 1c. When an internal Mu1 fragment was used as a probe (left), modified Mu1 elements were detected in lane $a$ but not in lane b. Unmodified Mu1 elements migrate at 1.7 and $1.3 \mathrm{~kb}$ (arrows). To test for partial enzyme activity, the same nitrocellulose filter was stripped and reprobed with a 900-bp ClaI fragment from the pet $B$ gene from maize chloroplast DNA that hybridizes to HinfI fragments of 800 and 550 bp in each sample (right). Partial digestion products are barely detectable but are at the same level in $a$ and $b$. 

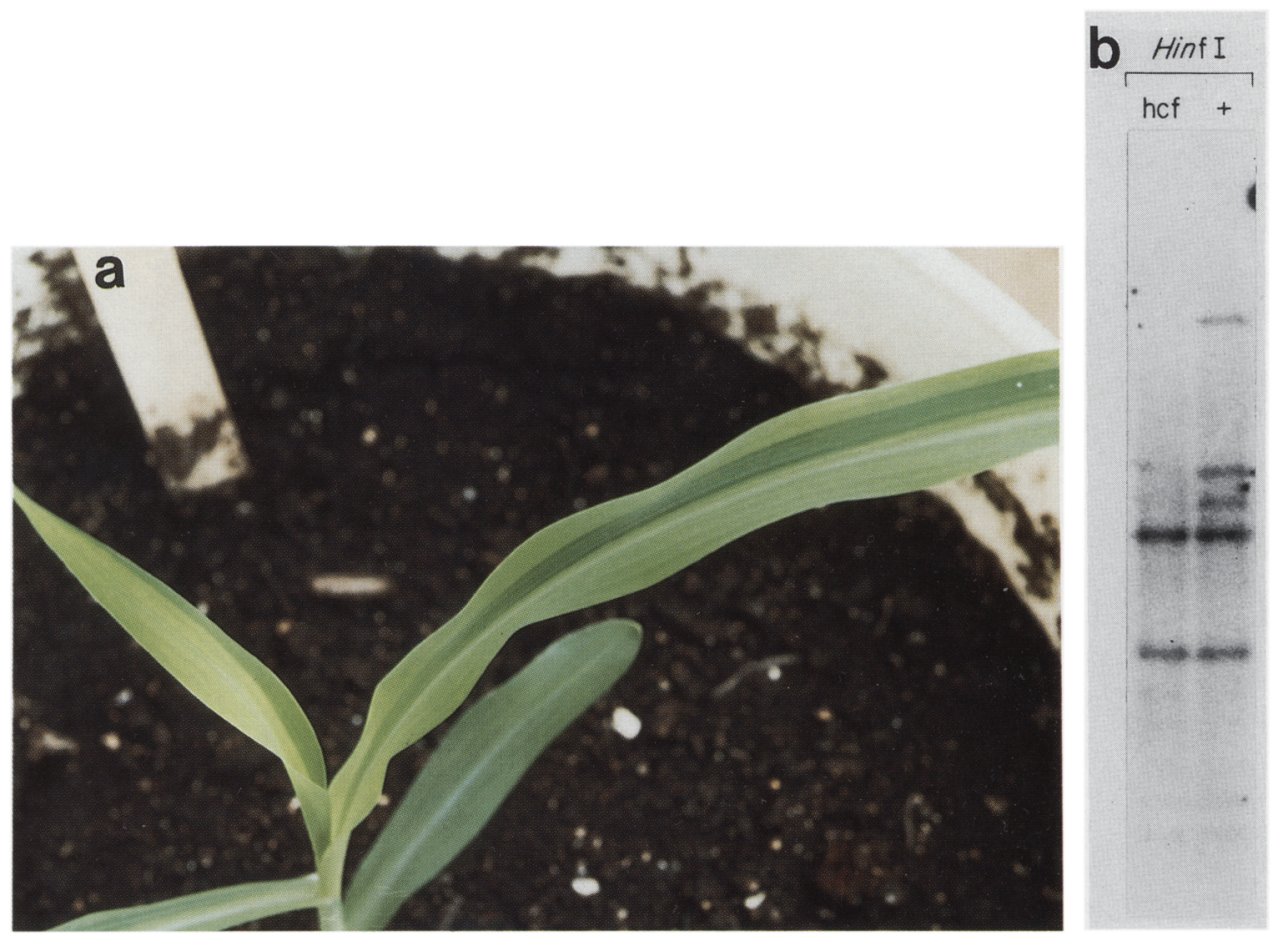

Figure 6. Modification at the $h c f 106$ locus in somatic sectors. (a) An example of a quarter-leaf sector that arose in the second leaf of a mutant seedling and passed in a clonal fashion from the margin to the midrib of successive leaves. Mutant tissue is pale green, whereas phenotypically wild-type tissue is dark green. $(b)$ DNA from mutant $(\mathrm{hcf})$ and phenotypically wild-type $(+\mid$ tissue from the sectored leaf in $a$ was digested with HinfI and subjected to Southern analysis using the hcf106 probe described in Fig. 3. The three larger fragments in DNA from wild-type tissue (of $2.7,1.8$, and $1.65 \mathrm{~kb}$ ) represent modification within and around the Mu1 element. The 2.7- and 1.65-kb fragments comigrate with those shown in Fig. 3. The 1.8-kb fragment probably represents modification in both $\mathrm{Mu}$ terminal repeats without modification outside the element. However, the site downstream from Mu1 may also be affected (see Fig. 3). The smaller 300-bp fragment described in Fig. 3 was run off this gel.

sector, and from the adjacent mutant tissue and was subjected to Southern analysis using a probe from the hcf106 locus. Digestion with SstI revealed that both samples were homozygous for the mutant hcf106 allele (data not shown). However, digestion with HinfI (Fig. 6b) showed that the dark green stripe $(+)$ had three large Hinfl fragments not found in the adjacent mutant tissue (hcf). These fragments result from heterogenous HinfI modification at one, two, or three sites in and around the Mu1 element at the locus (for details, see Fig. 3).

Plants containing large wild-type sectors (such as the one in Fig. 6) were often viable, and several mosaic plants homozygous for the mutant allele were raised to maturity. In one case, such a developmental mosaic was self-pollinated to yield both phenotypically normal and mutant progeny. This suggests that clonal lineages containing modified and unmodified elements are heritable through meiosis and into the next generation. Similarly, a number of heterozygous parents that contained some modified elements yielded a reduced number of mutant progeny on self-pollination (solid squares with asterisks in Fig. 1a). These mutant progeny had only unmodified elements, although most of their siblings had modified elements (data not shown). Presumably, the parents were also mosaics, but, being heterozygotes, their pigmentation was normal.

\section{Clones containing modified Mu1 elements arise progressively during development}

Sectored plants showed an interesting relation between the size of wild-type sectors and the developmental age of the sectored leaf. In the example shown in Figure 7a, the proportion of wild-type tissue increased in each successive leaf that emerged, until, by the seventh leaf, no phenotypically mutant tissue remained and the plant was wild-type and viable. Southern analysis of DNA from wild-type and mutant tissue again demonstrated that the wild-type sectors contained hypermodified Mu1 elements relative to the mutant tissue (Fig. 7a, leaf 2, lanes $a$ and $b$, respectively). Ten centimeters of leaf tissue from the tip of each leaf was also analyzed for Mu1 modification as was done previously. Figure $7 \mathrm{a}$ shows that the first leaf (which had only mutant tissue; data not shown/ had only unmodified elements, whereas the third, fourth, fifth, sixth, and seventh leaves had progressively fewer unmodified elements and progressively more modified elements. The observed increase in the proportion of modified elements reflects the increasing proportion of phenotypically wild-type tissue in each leaf.

Of 20 mosaic plants, 19 imitated this pattern of striping (the exception did not survive beyond the third 

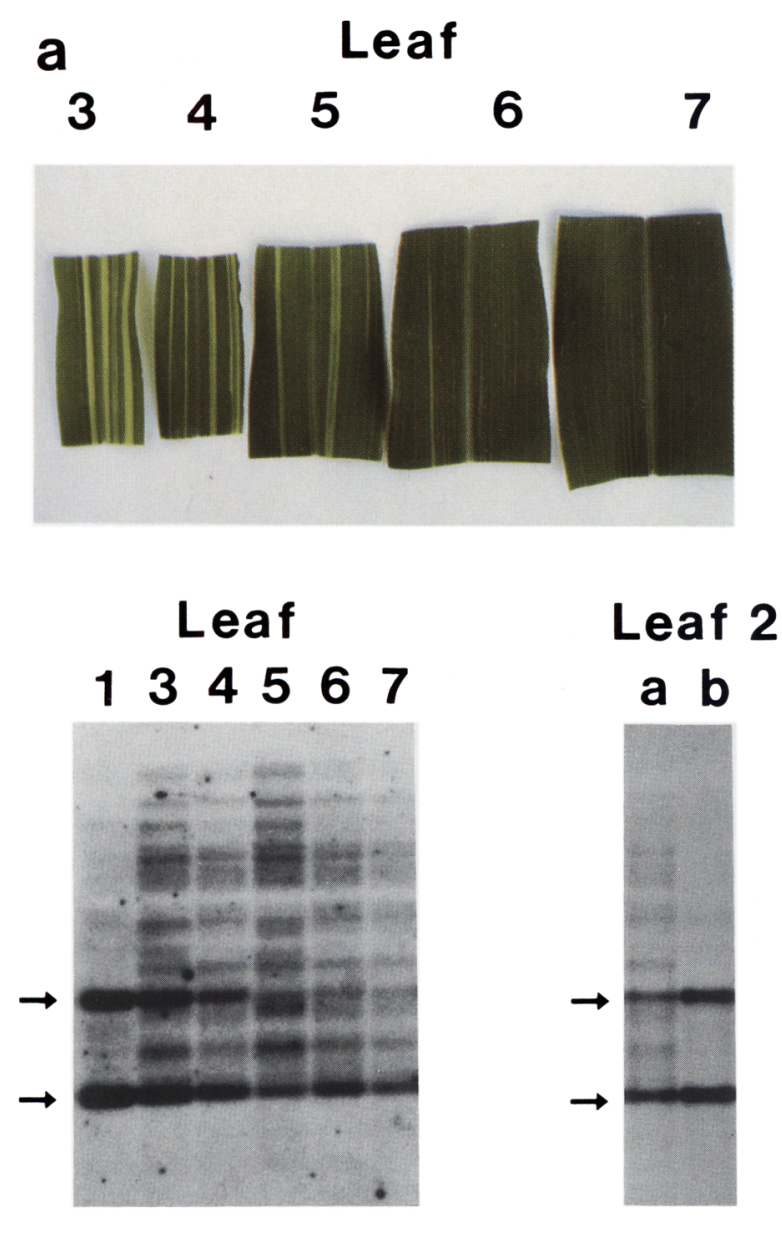

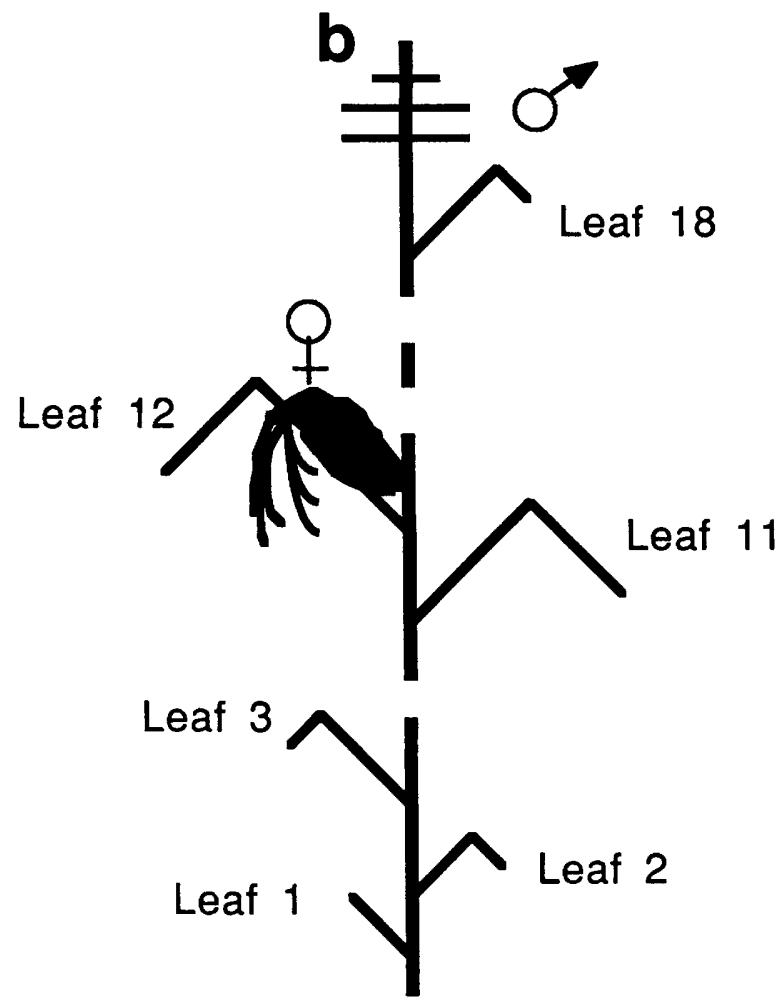

Figure 7. Distribution of clonal sectors in mosaic plants. (a) Leaf sections from the third, fourth, fifth, sixth, and seventh leaves of a mosaic plant. Mutant tissue is pale, whereas phenotypically wild-type tissue is dark green. Southern analysis showed that this plant was homozygous for the mutant hcf106 allele (not shown). The first leaf was almost entirely mutant, whereas the second leaf had a broad dark green stripe. DNA was extracted from the first leaf and from the leaf sections. shown /which were harvested at the same time) and was subjected to HinfI digestion and Southern analysis, as in Fig. 1. DNA was also extracted from the dark green stripe (lane a) and the (mostly) mutant remainder (lane b) of the second leaf (leaf 2). Each sample was digested with HinfI and analyzed for Mu1 element modification and complete digestion, as in Fig. 1. Arrows indicate fragments derived from unmodified elements. $(b)$ A diagram of a maize plant, showing the order of the leaves and the arrangement of the male and female flowers.

leaf), although details varied from plant to plant. The plant shown in Figure 6, for example, acquired more dark green sectors in the upper leaves but was not completely wild-type until leaf 13 . Nonetheless, each plant had large sectors in successive leaves, demonstrating that changes in the proportion of cells retaining $\mathrm{Mu}$ activity had occurred in the apical meristem, as discussed below.

\section{Discussion}

\section{hcf106 is suppressed in Mu-inactive lines}

We describe the first example of a suppressible mutation induced by Robertson's Mutator in maize. Suppression of the mutant allele hcf106 is observed when the $\mathrm{Mu}$ tator transposable elements are inactive, so that plants containing modified' Mu1 elements adopt a wild-type phenotype. However, suppression of the mutant phenotype was shown to be reversible by crosses to $\mathrm{Mu}$-active plants: When the $M u 1$ elements from suppressed plants were reactivated in such crosses, the mutant phenotype reappeared in resulting progeny. Suppression of the mutant phenotype occurs at a high frequency in the B73 inbred background used. Of 100 heterozygote outcrosses, only 26 gave rise to mutant progeny when selfed, though 50 would be expected to inherit the mutant allele. The proportion of mutants in these selfs varied from one-quarter to one-twentieth or less. Similarly, only 17 of 41 plants derived by selfing heterozygotes (roughly half the expected number) segregated mutants when they were self-pollinated. These numbers are consistent with the high proportion of plants found to carry modified $\mathrm{Mu} 1$ elements in these lines $(30$ of 70 unselected plants; see Table 1). 
In data presented elsewhere (Martienssen et al. 1989), we showed that accumulation of a $1.2-\mathrm{kb}$ transcript from the hcf106 locus was blocked in mutant cells by insertion of a Mu1 element. In contrast, suppressed plants had wild-type levels of this transcript, even when homozygous for the insertion. This showed that gene expression was directly influenced by $M u$ activity in a reversible fashion. Subsequently, $\mathrm{S} 1$ mapping and primer extension experiments have mapped the $M u 1$ element to the $5^{\prime}$-untranslated region of the $h c f 106$ gene, very close to one of three initiation sites (A. Barkan and R. Martienssen, in prep.). In this regard, hcf106 resembles suppressible mutations in yeast caused by insertion of $T y$ near the initiation site of affected genes. Although the molecular mechanism of suppression by $M u$ is unknown, unlinked suppressor loci in yeast are thought to encode factors that interact with promoter/enhancer regions found within the Ty transposable element, thus enabling adjacent gene expression (e.g., Fassler and Winston 1988; Eisenmann et al. 1989/. This contrasts with the mechanism of suppression of Spm-induced alleles in maize, which is thought to involve transcriptional readthrough and splicing of defective transposons inserted into the transcribed region of the affected gene (Kim et al. 1987; Gierl et al. 1988; Fedoroff 1989).

Suppression of the mutant phenotype is accompanied by DNA modification of the $M u 1$ elements in affected plants. Furthermore, hybridization with probes from the hcf106 locus, itself, showed that the Mu1 element at the locus is also methylated in homozygous plants from suppressed lines. This raises the possibility that increased modification at the $h c f 106$ locus, itself, may be responsible for changes in gene expression. However, an exceptional heterozygous plant was observed that had unmodified Mu1 elements but whose homozygous progeny failed to express the mutant phenotype. At least some of these progeny also had unmodified elements, including the one at the hcf106 locus. Nonetheless, the Mu1 elements in these progeny appeared to be inactive and could be reactivated by crossing to $\mathrm{Mu}$-active plants, a procedure that restored the mutant phenotype to homozygous backcross progeny. Thus, DNA modification at the Hinfl sites in $M u 1$ is not always required for loss of $\mathrm{Mu}$ activity (as observed by Bennetzen et al. 1988) and suppression of the mutant phenotype. This may reflect the existence of another inactivation mechanism independent of DNA modification (such as segregation of a trans-acting autonomous element). Alternatively, modification may be an outcome of inactivation, rather than a cause, and may take longer to become established in some inactive lines than in others. Finally, methylation of cytosines in and around $M u 1$ that are not part of restriction sites may also be important, but this can only be determined by genomic sequencing.

\section{Mu DNA modification occurs in somatic sectors}

Plants carrying the mutant hcf106 allele respond to changes in $\mathrm{Mu}$ activity that occur from generation to generation. They also respond to changes that occur within a plant. As observed by others (Robertson 1983; Walbot 1986), no simple genetic model can account for the observed loss of $M u$ activity in most pedigrees. Instead, the data presented here support an epigenetic model for the loss of $\mathrm{Mu}$ activity and the modification of Mu1 elements. According to this model, $M u$ activity can be lost from individual cells, or clonally related groups of cells, giving rise to somatic sectors during plant development. Direct analysis of DNA from sectored leaves, using the hcf106 phenotype as a marker, has shown that $\mathrm{Mu}$-inactive sectors contain modified elements, whereas $\mathrm{Mu}$-active tissue has unmodified elements. As individual sectors can occupy as much as one-quarter of the leaf width, switches to a $M u$-inactive phase can occur just a few cell divisions from the zygote and remain stably inherited during leaf development /Coe and Neuffer 1978). HinfI modification at the hcf106 locus was also observed in DNA from a $\mathrm{Mu}$-inactive sector but not in the adjacent mutant tissue. Hybridizing fragments were observed in this sector with one, two, or three modified sites: two sites from within the Mu1 element, and one from the upstream flanking DNA. This heterogeneity may reflect progressive modification following an initial (clonally inherited) inactivation event.

The presence of somatic sectors that contain modified elements is an important consideration when isolating DNA from plants not marked by mutations like hcf106. First, "partially modified elements," such as those observed in leaf DNA isolated from plants that carry cycling Ac (Chomet et al. 1987) or Spm elements (Banks et al. 1988), may suggest the existence of such sectors. In the case of $M u 1$, residual unmodified elements are frequently observed in DNA samples from plants in which most of the elements are modified (e.g., Fig. 1c). This may represent the existence of $\mathrm{Mu}$-active cells in mosaics (as in Fig. 7). However, other factors may also be involved, such as unmodifiable elements located in CpG islands (Antequera and Bird 1988). Second, mosaic plants can give rise to both modified and unmodified progeny (as illustrated by the partially modified heterozygotes shown in the pedigree in Fig. 1), which may confuse subsequent genetic analysis.

\section{Mu-activity is progressively lost during maize development}

The distribution of wild-type sectors in mosaic plants revealed a striking correlation with the developmental position of affected leaves. Lower (earlier) leaves were mostly mutant, whereas upper (later) leàves were mostly wild-type. The point at which wild-type cells occupied the entire circumference of the plant varied from leaf 3 to leaf 13 in different families, but all leaves above this point only had wild-type cells. In contrast to this somatic behavior, reactivation of $\mathrm{Mu}$ elements by crossing between active and inactive plants appeared to occur immediately at the time of fertilization, as fully mutant $F_{1}$ progeny were observed.

In principle, this pattern could be the result of selection for phenotypically wild-type cells over mutant 
(nonphotosynthetic) cells in the apical meristem. We regard this as unlikely for the following reasons. First, such selection would have to occur in the early embryo (see below) when all cells are photosynthetically inactive. Other nonphotosynthetic sectors in maize / such as those induced using ring chromosomes/ are not selected against at this stage (Poethig et al. 1986). Second, mutant hcf106 plants are frequently observed with small sectors of wild-type leaf tissue that do not progressively increase in size in successive leaves. These are thought to be revertant sectors that, as in other $\mathrm{Mu}$ alleles, occur relatively late in development (Robertson 1978; Lillis and Freeling 1986). Small revertant sectors cannot be distinguished phenotypically from those caused by suppression, but rare large revertant sectors can be distinguished by Southern blotting (Martienssen et al. 1989). A one-eighth leaf revertant sector was found on the first leaf of a mutant plant and identified in this way. This sector grew smaller on the second leaf and was not observed on the third (not shown). Therefore, revertant cells were not selected over mutant ones in this plant. Finally, a progressive increase in $\mathrm{Mu}$ DNA modification has been observed in plants that do not carry hcf106 or any other suppressible mutation (Bennetzen et al. 1988). In this case, although the clonal nature of the switching events could not be observed, the increase in modification could not easily be explained by selection. Thus, although selection for $\mathrm{Mu}$-inactive cells cannot be ruled out, we favor a model in which the position of a given cell in the meristem determines the likelihood of it adopting an inactive phase.

The lower leaves of a maize plant develop from leaf primordia that arise from the lower part of the shoot meristem, whereas upper leaves develop later from cells nearer the tip (Coe and Neuffer 1978; McDaniel and Poethig 1988). The first six leaves are formed in the developing embryo, and the remainder emerge postembryonically following germination. During embryo development, cells at the lower periphery of the meristem are thought to adopt more restricted fates than cells higher up, both in terms of the number of leaves that they contribute to and the position of these leaves on the plant (Poethig et al. 1986). However, such fates can only be predicted in a general way at any given point in development (McDaniel and Poethig 1988). Cells at the tip of the meristem in the late proembryo, for example, will give rise to large sectors in the upper leaves (above leaf 4) but only small sectors (if any) in the lower leaves of the mature plant (Poethig et al. 1986).

Thus, large wild-type sectors observed in hcf106 plants are derived from dividing cells near the tip of the shoot meristem that "turn off" progressively during development. Such sectors arise in each successive leaf, until in the upper leaves, most cells contain inactive $M u$ elements. This observation may be interpreted in two ways. First, the longer a given cell lineage spends in the meristematic condition, the more likely it is to adopt an inactive phase. This is because cells near the tip differentiate into leaf primordia later than those at the periphery and, consequently, spend longer in the undiffer- entiated state. Alternatively, cells near the tip of the meristem may switch off preferentially following anticlinal divisions that give rise to peripheral cells during meristem formation (Poethig et al. 1986; McDaniel and Poethig 1988). Switching events may not be restricted to apical cells, however, as smaller sectors are also observed in mutant leaves, and it is not known whether these represent revertant or suppressed clones of cells.

Somatic sectoring may provide an explanation for the reciprocal effect observed in crosses between active and inactive plants. That is, some active plants (but not all) are more likely to lose $\mathrm{Mu}$ activity through the male than through the female (Walbot 1986; Bennetzen 1987). As illustrated in Figure $7 \mathrm{~b}$, the female flower develops from a lower axillary bud, whereas the (male) tassel develops from the apex of the plant. Because of the relationship between developmental position and size of inactive sector, the male flower may contain larger inactive sectors than the female flower, resulting in a higher proportion of gametes carrying inactive $\mathrm{Mu}$. According to this model, crosses involving unsectored plants would show no reciprocal effect. Other models that invoke cytoplasmic factors have also been proposed (Walbot 1986), but maternal effects would be expected in every cross, if this were the case, and are not always observed (Bennetzen 1987; V. Sundaresan and M. Freeling, unpubl.).

DNA modification of maize transposons is reminiscent of other epigenetic phenomena in plants and animals

The hcf106 allele is genetically similar to a number of Spm-suppressible mutations of kernel color genes in maize that respond to $S p m$ activity, rather than $M u$ activity (Fedoroff 1983). Inactive Spm elements are also hypermodified (Banks et al. 1988), as are inactive Ac elements (Chomet et al. 1987). Somatic sectors that apparently contain inactive Spm or $A c$ elements can arise during plant and endosperm development (McClintock 1965|. Furthermore, some cycling Spm elements adopt an inactive phase more frequently in progeny derived from upper ears and tassels than those from lower ears and tillers (Fedoroff and Banks 1988). However, unlike $\mathrm{Mu}$ elements, changes in modification and genetic activity of Spm and Ac elements can be mapped to the autonomous element (McClintock 1965; Banks et al. 1988). It remains to be seen whether DNA modification of $\mathrm{Mu}$ transposons is responsible for the loss of their activity, is a consequence of this loss, or simply maintains inactivated elements in the inactive state.

The suppression of hcf106 is reminiscent of the behavior of paramutant alleles of the $R$ (kernel color) and $B$ (booster) loci in maize (Coe 1966; Brink et al. 1968), and the nivea locus in Antirrhinum (Harrison and Carpenter 1973). Paramutation is the heritable alteration of the expression of one (paramutable) allele promoted by the presence of another (paramutagenic) allele in the heterozygote. After the paramutagenic allele segregates away, the paramutant phenotype progressively reverts, often in somatic sectors, during subsequent generations. A reciprocal effect in the mode of transmission of the paramu- 
tant phenotype has also been noted, at least in the case of $B$ in maize (Coe 1966) and nivea in Anthirrhinum (Harrison and Carpenter 1973). In Antirrhinum, paramutation has been shown to be associated with transposable elements (Upadhyaya et al. 1985; Hudson et al. 1987), whereas in maize, the involvement of transposons and DNA modification have been suggested (McClintock 1965; Coe 1966; Brink et al. 1968).

The similarity between these epigenetic phenomena suggests that a common developmental mechanism may be involved in the regulation and modification of plant transposable elements. It has been proposed that this mechanism participates in a variety of developmental processes in plants (Fedoroff and Banks 1988; Fedoroff 1989|, but the relationship between somatically heritable DNA modification and plant development has yet to be established. Certainly, the ability of plant transposons to subvert gene expression in response to genetic and epigenetic signals during development represents a powerful mode of mutational and evolutionary change (McClintock 1965; Coen et al. 1986).

It is interesting to compare the behavior of animal and plant cells with regard to DNA modification. Somatic changes in the pattern of DNA modification, such as X chromosome inactivation (Lock et al. 1987), can be clonally inherited in animals (for review, see Holliday 1987). However, pattern changes are not passed to the next generation unless they occur in the germ line /Silva and White 1988), as exemplified by the phenomenon of chromosomal imprinting (Surani et al. 1988). It has been proposed that the loss of cytosine modification in successive somatic cell divisions leads to a deleterious accumulation of epigenetic defects related to aging (Holliday 1987; Wareham et al. 1987; McGowan et al. 1989).

In this sense, hcf106 represents such a defect. Activation of $M u$ and the associated loss of DNA modification abolish expression of the hcf106 gene and result in a lethal nonphotosynthetic phenotype. However, in plants undergoing a change of phase, this defect is progressively corrected in specific cell lineages during plant development. Thus, the number of cells containing modified $M u$ elements increases as the meristem ages. This may reflect the evolution of a mechanism to prevent epigenetic defects from reaching the germ line: Unlike animal germ cells, plant meiocytes arise from somatic lineages. Correction of epigenetic defects in somatic cells would thus prevent transmission of such defects to the next generation.

\section{Methods}

Plant material

hcf106 was identified originally as a sector on an ear derived by outcrossing Robertson's Mutator to the inbred line B73 (Pioneer Hi-bred International). Two kernels from this sector gave rise to heterozygous plants (hcf106-6 and hcf106-13) that segregated mutant progeny on self-pollination. Normal siblings from these families were intercrossed to confirm allelism and self-pollinated and outcrossed to B73, giving rise to the pedigree shown in Figure 1. Each plant in the pedigree was self-pollinated, and
$50-200$ kernels from each ear were planted to screen for mutant progeny.

In reactivation crosses, the $\mathrm{Mu}$-active parents were the normal siblings from self-pollinated families segregating mutants in a $3: 1$ ratio. Two-thirds of these were expected to carry the mutant allele (the one in four mutant seedlings died). Suppressed parents were the progeny of heterozygous plants that carried the mutant allele (as judged by Southern analysis; see Fig. 1) but gave rise to no mutants on self-pollination. Threequarters of these parents were expected to carry the mutant allele. Thus, one-half of the crosses $(2 / 3 \times 3 / 4)$ between $M u$-active and suppressed parents would yield at least some progeny that were homozygous for the mutant allele.

\section{DNA isolation and analysis}

DNA was isolated from individual seedlings or from mature leaves by a miniprep procedure described elsewhere (Martienssen et al. 1989), digested with 5-10 U/ $\mathrm{gg}$ of SstI or HinfI according to the recommendations of the manufacturer, fractionated on agarose gels, and transferred to nitrocellulose membranes by the procedure of Southern. For Southern analysis of $M u$ elements, membranes were prehybridized and then hybridized to the 1.3-kb internal HinfI fragment from Mu1 (pMJ9; Bennetzen et al. 1984), which was gel-purified and radiolabeled by random priming, as described previously (Martienssen et al. 1989). Hybridization to $\mathrm{Mu}$ elements only related to $\mathrm{Mu} 1$ by their terminal repeats was avoided by washing at high stringency $\left(0.1 \times \mathrm{SSC}, 0.1 \%\right.$ SDS at $\left.65^{\circ} \mathrm{C}\right)$. Complete digestion was assayed by stripping the probe from the HinfI blots at $95^{\circ} \mathrm{C}$ in $10 \mathrm{~mm}$ Tris-HCl (pH 8), $1 \mathrm{~mm}$ EDTA, for $2 \mathrm{hr}$ and reprobing with a maize chloroplast DNA probe (see Fig. 5). Probes from the hcf106 locus were hybridized under the same conditions but were washed at $0.2 \times \mathrm{SSC}, 0.1 \% \mathrm{~S} \mathrm{DS}, 65^{\circ} \mathrm{C}$.

\section{Acknowledgments}

We thank Judy Yamaguchi for technical assistance and Kelly Dawe, Tony Pryor, Kevin Moses, Paul Chomet, and Ian Sussex for critical reading and helpful discussions. This work was supported by fellowships from EMBO (to R.M.) and the National Institutes of Health (to A.B.), and by grants from the National Science Foundation (to M.F.) and the U.S. Department of Agriculture Competitive Grants Program (to W.T.).

\section{References}

Alleman, M. and M. Freeling. 1986. The $M u$ transposable elements of maize: Evidence for transposition and copy number regulation during development. Genetics 112: 107119.

Antequera F. and A.P. Bird. 1988. Unmethylated CPG islands associated with genes in higher plant DNA. EMBO $J$. 7: 2295-2299.

Banks J.A., P. Masson, and N.V. Fedoroff. 1988. Molecular mechanisms in the developmental regulation of the maize Suppressor-mutator transposable element. Genes Dev. 2: $1364-1380$.

Barkan A., D. Miles, and W.C. Taylor. 1986. Chloroplast gene expression in nuclear, photosynthetic mutants of maize. EMBO I. 5: 1421-1427.

Barker R.F., D.V. Thompson, D.R. Talbot, J. Swanson, and J.L. Bennetzen. 1984. Nucleotide sequence of the maize transposable element Mu1. Nucleic Acids Res. 12: 5955-5967. 
Bennetzen J.L. 1984. Transposable element $M u 1$ is found in multiple copies only in Robertson's mutator maize lines. $J$. Mol. Appl. Genet. 2: 519-524.

Bennetzen J.L., J. Swanson, W.C. Taylor, and M. Freeling. 1984. DNA insertion in the first intron of maize $A d h 1$ affects message levels: cloning of mutant and progenitor alleles. Proc. Natl. Acad. Sci. 81: 4125-4128.

Bennetzen, J.L. 1987. Covalent DNA modification and the regulation of Mutator element transposition in maize. Mol. Gen. Genet. 208: 57-62.

Bennetzen J.L., R.P. Fracasso, D.W. Morris, D.S. Robertson, and M.J. Skogen-Hagenson. 1987. Concomitant regulation of Mu1 transposition and Mutator activity in maize. Mol. Gen. Genet. 208: 45-51.

Bennetzen J.L., W.E. Brown, and P.S. Springer. 1988. The state of DNA modification within and flanking maize transposable elements. In Plant transposable elements (ed. O.E. Nelson), pp. 237-251. Plenum Press, New York.

Brink, R.A., E.D. Styles, and J.D. Axtell. 1968. Paramutation: Directed genetic change. Science 159: 161-170.

Cedar, H. 1988. DNA methylation and gene activity. Cell 53: 3-4.

Chandler, V.L. and V. Walbot. 1986. DNA modification of a maize transposable element correlates with loss of activity. Proc. Natl. Acad. Sci. 83: 1767-1771.

Chomet, P., S. Wessler, and S. Dellaporta. 1987. Inactivation of the maize transposable element Activator $(A C)$ is associated with its DNA modification. EMBO I. 6: 295-302.

Coe, E.H., Jr. 1966. The properties origin and mechanism of conversion-type inheritance at the $\mathrm{B}$ locus in maize. $\mathrm{Ge}$ netics 53: 1035-1063.

Coe, E.H., Jr. and M.G. Neuffer. 1978. Embryo cells and their destinies in the corn plant. In The clonal basis of development (ed. S. Subtelny and I. Sussex), p. 113. Academic Press, New York.

Coen, E.S., R. Carpenter, and C. Martin. 1986. Transposable elements generate novel spatial patterns of gene expression in Antirrhinum majus. Cell 47: 285-296.

Eisenmann, D.M., C. Dollard, and F. Winston. 1989. SPT15, the gene encoding the yeast TATA binding factor TFIID, is required for normal transcription initiation in vivo. Cell 58: 1183-1191.

Fassler J. and F. Winston. 1988. Isolation and analysis of a novel class of suppressor of Ty insertion mutations in S. cerevisiae. Genetics 118: 203-212.

Fedoroff, N.V. 1983. Controlling elements in maize. In Mobile genetic elements (ed. J.A. Shapiro), pp. 1-63. Academic Press, New York.

Fedoroff, N.V. and J.A. Banks. 1988. Is the Suppressor-mutator element controlled by a basic developmental mechanism? Genetics 120: 559-570.

Fedoroff, N.V. 1989. About maize transposable elements and plant development. Cell 56: 181-191.

Freeling, M. 1988. Mutagenesis using Robertson's Mutator lines and consequent insertions at the Adhl gene in maize. In Plant transposable elements (ed. O.E. Nelson), pp. 279-289. Plenum Press, New York.

Gierl, A., S. Lutticke, and H. Saedler. 1988. TnpA product encoded by the transposable element En-l of Zea mays is a DNA binding protein. EMBO I. 7: 4045-4053.

Harrison, B.J. and R. Carpenter. 1973. A comparison of the instabilities at the nivea and pallida loci in Antirrhinum majus. Heredity 31: 309-323.

Holliday, R. 1987. The inheritance of epigenetic defects. Science 238: 163-169.

Hudson, A., R. Carpenter, and E.S. Coen. 1987. De novo activation of the transposable element Tam2 of Antirrhinum majus. Mol. Gen. Genet. 207: 54-59.

Kim, H.-Y., J.W. Schiefelbein, V. Raboy, D.B. Furtek, and O.E. Nelson. 1987. RNA splicing permits expression of a maize gene with a defective Suppressor-mutator transposable element insertion in an exon. Proc. Natl. Acad. Sci. 84: 58635867.

Kubli, E. 1986. Molecular mechanisms of suppression in Drosophila. Trends Genet. 2: 204-209.

Lillis, M. and M. Freeling. 1986. $\mathrm{Mu}$ transposons in maize. Trends Genet. 2: 183-188.

Lock, L.F., N. Takagi, and G.R. Martin. 1987. Methylation of the Hprt gene on the inactive $\mathrm{X}$ occurs after chromosome inactivation. Cell 48: 39-46.

Martienssen R.A., A. Barkan, A. Scriven, and W.C. Taylor. 1987. Identification of a nuclear gene involved in thylakoid structure. In Plant membranes (ed. C. Laever and H. Sze), pp. 181-192. Alan R. Liss, New York.

Martienssen R.A., A. Barkan, M. Freeling, and W.C. Taylor. 1989. Molecular cloning of a maize gene involved in photosynthetic membrane organisation that is regulated by Robertson's Mutator. EMBO I. 8: 1633-1639.

Masson P., R. Surosky, J.A. Kingsbury, and N.V. Fedoroff. 1987. Genetic and molecular analysis of the Spm-dependent a-m2 alleles of the maize $a$ locus. Genetics 177: 117-137.

McClintock B. 1958. The suppressor-mutator system of control of gene action in maize. Carnegie Inst. Wash. Year Book 57: 415-429.

- 1965. The control of gene action in maize. Brookhaven Symp. Biol. 18: 162-164.

McDaniel, C.N. and R.S. Poethig. 1988. Cell lineage patterns in the shoot apical meristem of the germinating maize embryo. Planta 175: 13-22.

McGowan R., R. Campbell, A. Peterson, and C. Sapienza. 1989. Cellular mosaicism in the methylation and expression of hemizygous loci in the mouse. Genes Dev. 3: 1669-1676.

Miles D. (1982). The use of mutations to probe photosynthesis in higher plants. In Methods in chloroplast molecular biology (ed. M. Edelman), pp. 76-107. Elsevier, Amsterdam.

Poethig, R.S., E.H. Coe, Jr., and M.M. Johri. 1986. Cell lineage patterns in maize embryogenesis: A clonal analysis. Dev. Biol. 117: 392-404.

Robertson, D.S. 1978. Characterisation of a mutator system in maize. Mutat. Res. 51: 21-28.

- 1983. A possible dose-dependent inactivation of $\mathrm{mu}$ tator in maize. Mol. Gen. Genet. 191: 86-90.

Schwarz-Sommer, Zs., N. Shepherd, E. Tacke, A. Gierl, W. Rohde, L. Leclerq, M. Mattes, R. Berndtgen, P.A. Peterson, and $H$. Saedler. 1987. Influence of transposable elements on the structure and function of the $A 1$ gene of Zea mays. $E M B O$ I. 6: 287-294.

Silva, A.J. and R. White. 1988. Inheritance of allelic blueprints for methylation patterns. Cell 54: 145-152.

Sundaresan, V. and M. Freeling. 1986. An extrachromosomal form of the $M u$ transposons of maize. Proc. Natl. Acad. Sci. 84: 4924-4928.

Surani, M.A., W. Reik, and N.D. Allen. 1988. Transgenes as molecular probes for genomic imprinting. Trends Genet. 4: $59-62$.

Swain, J.L., T.A. Stewart, and P. Leder. 1987. Parental legacy determines methylation and expression of an autosomal transgene: A molecular mechanism for parental imprinting. Cell 50: 719-727.

Taylor, L.P. and V. Walbot. 1987. Isolation and characterization of a $1.7 \mathrm{~kb}$ transposable element from a mutator line of maize. Genetics 117: 297-307.

Upadhyaya, K.C., H. Sommer, E. Krebber, and H. Saedler. 1985. The paramutagenic line niv- 44 has a $5.7 \mathrm{~kb}$ insert, Tam 2 , in 
the chalcone synthase gene of Antirrhinum majus. Mol. Gen. Genet. 199: 201-206.

Walbot V. 1986. Inheritance of mutator activity in Zea mays as assayed by somatic instability of the bz2-mu1 allele. $\mathrm{Ge}$ netics 114: 1293-1312.

Wareham, K.A., M.F. Lyon, P.H. Glenister, and E.D. Williams. 1987. Age related reactivation of an X-linked gene. Nature 327: $725-727$.

Winston F., K.J. Durbin, and G.R. Fink. 1984. The SPT3 gene is required for normal transcription of Ty elements in $S$. cerevisiae. Cell 39: 675-682.

Yen, P.H., P. Patel, A.C. Chinault, T. Mohandas, and L.J. Shapiro. 1984. Differential methylation of hypoxanthine phosphoribosyltransferase genes on active and inactive human $\mathrm{X}$ chromosomes. Proc. Natl. Acad. Sci. 81: 1759-1763. 


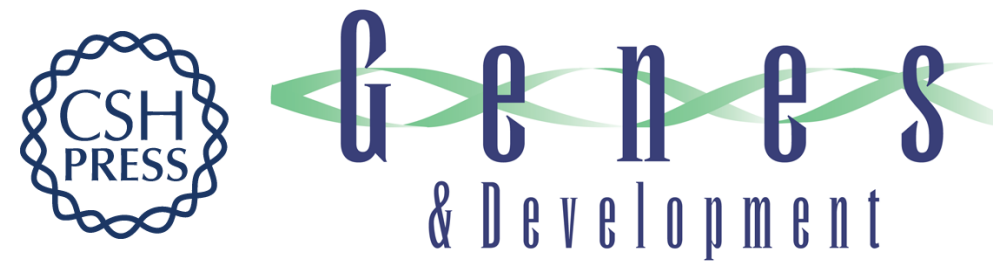

\section{Somatically heritable switches in the DNA modification of Mu transposable elements monitored with a suppressible mutant in maize.}

R Martienssen, A Barkan, W C Taylor, et al.

Genes Dev. 1990, 4:

Access the most recent version at doi:10.1101/gad.4.3.331

References This article cites 47 articles, 14 of which can be accessed free at: http://genesdev.cshlp.org/content/4/3/331.full.html\#ref-list-1

License

Email Alerting Service

Receive free email alerts when new articles cite this article - sign up in the box at the top right corner of the article or click here.

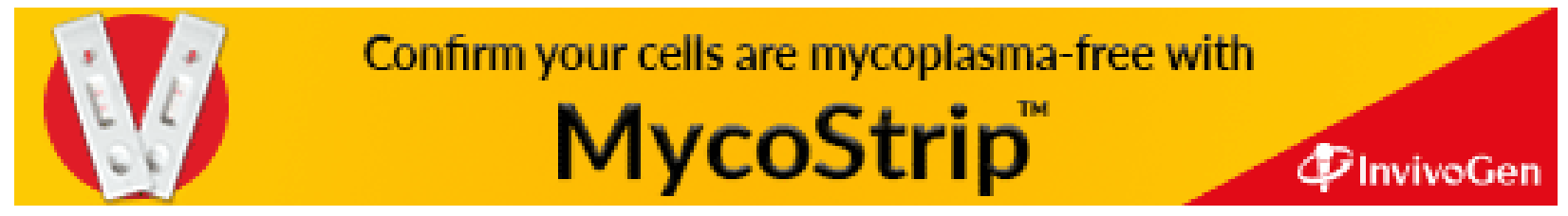

